\title{
界面活性剂膜の厚み摇らぎ
}

\author{
長尾 道弘, 垪和 卓親 ${ }^{*}$ \\ (インディアナ大学物理学科, オクラホマ大学航空機械工学科 ${ }^{*}$ )
}

\section{Thickness Fluctuations in Surfactant Bilayers}

\author{
Michihiro Nagao and Takumi Hawa ${ }^{*}$ \\ Department of Physics, Indiana University and
}

School of Aerospace and Mechanical Engineering, University of Oklahoma*

\section{0}

\begin{abstract}
Surfactant bilayers experience thickness fluctuations even when the bilayer is swollen by small amount of solvent. Neutron scattering experiments reveal the characteristic features of the fluctuations. Neutron spin echo (NSE) in particular gives information about time scales of the motion and the fluctuation amplitude. Calculations using a simple computer model suggest that the static parameters, such as fluctuation amplitude, are measurable from small-angle scattering (SAS) data. Combination of SAS, NSE, and computer model provides essential knowledge on the bilayer dynamics. Calculations based on deformation free energy model of elastic membranes prove the feasibility of the scattering experiments and the computer model.

Keywords: surfactant membrane, dynamics, small-angle scattering, neutron spin echo, computer simulation, deformation free energy
\end{abstract}

1.はじめに

両親媒性分子は水及び油への相溶性から自然界 に限らず工業的にも幅広く利用される。両親媒性 分子は水, 油界面に吸着し, 界面膜となって様々 な自発構造を形成する. 本稿では界面活性剂分子 が水中で形成する二分子膜に着目する. 二分子膜 は水中でベシクルやラメラ構造などを形成する.

これらの構造形成においては膜弾性エネルギーが 重要と考えられており，1970 年代の Helfrichによ る弾性エネルギーモデルによって構造形成が説明 される[1]. 膜の単位面積当りの弾性エネルギーは $f=\kappa\left(C_{1}+C_{2}-2 C_{0}\right) / 2+\bar{\kappa} C_{1} C_{2}$ で表され, 特徽的な 弾性定数 $\kappa$ と炎が得られる。これらは曲げ弾性定 数とサドルスプレイ弾性定数である. $C_{1}$ と $C_{2}$ は 膜の二つの主曲率, $C_{0}$ は膜の自発曲率である. 中 性子散乱法は，これら膜の弾性モデルに重要な定 数の決定に利用され, 特に中性子スピンエコー

（NSE）法は $\kappa$ と $\bar{\kappa}$ の決定に利用される[2,3]. し かし, Helfrich model は, 膜を厚みの無い弾性体と して取り扱っており, 膜の内部構造の議論には適 さない。

一方で, 細胞膜の主成分であるリン脂質膜の研 究では, 脂質膜と膜タンパク質の相互作用が機能 に重要であると考えられている。しかしながら， そのミクロスコピックな議論の多くは静的な描像 に基づいている. Huang を初めとする膜の変形自
由エネルギーモデル[4-7]の発展も相まって膜タン パク質の機能発現と膜の変形に深い関わりがある ことが指摘されている[8]. 近年では, 局所的な膜 の平衡構造とその運動が新たな研究対象として議 論可能になってきた.

中性子小角散乱（SANS）はタンパク質や膜の 構成成分のスケールを調べるのに適しており, 膜 内構造の観測が可能である。一方 NSE は，これら の長さのスケールでの運動状態を調べることが出 来る. NSE はこれまでも膜の曲げ運動の観測に利 用されてきた。一方で，より局所的な構造の協同 運動については,ほとんど議論が行われていない. 第 2 節では局所的な界面活性剂分子の協同運動の 一例として界面活性剂二分子膜及び少量の油によ って膨潤された擬二分子膜における厚み摇らぎに ついて紹介する[9-11].

コンピュータシミュレーション技術はこれらの スケールでのモデル計算を可能にし, 膜の曲げ運 動や厚み摇らぎについての議論が行われる[12]. 我々の NSE 実験結果の議論においても, コンピュ ータシミュレーションによる解析が，実験及び解 䣋に正当性を与えた[10]. 第 3 節では，簡単な膜 の運動をコンピュータモデルで計算することによ り, SANS データから運動に関わるパラメータを 推量する可能性を紹介する[13,14]. 


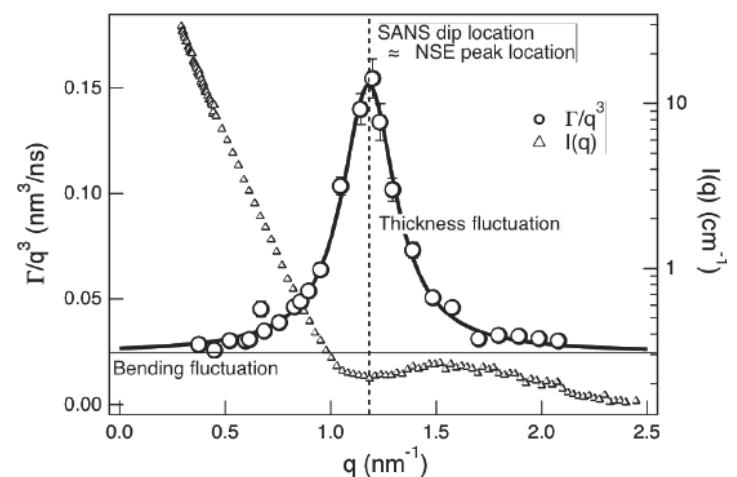

Fig. $1 q$-dependence of $\Gamma / q^{3}$ observed by NSE together with $I(q)$ observed by SANS. The solid curve is the fit to a Lorentzian, dashed vertical line shows the position of dip in SANS and peak in NSE data, and the horizontal line shows the contribution of bending to $\Gamma / q^{3}$. Error bars represent \pm 1 standard deviation.

第 4 節では Huang の提唱した変形自由エネルギ 一モデル[4]を用いたエネルギー計算の結果，膜の 厚み摇らぎが変形自由エネルギーモデルで説明で きることを紹介し[15], 第 5 節で本稿をまとめる.

\section{2. 非イオン界面活性剤膜の厚み摇らぎ観測}

NSE による厚み摇らぎの観察は 90 年代半ばの Farago らの実験に遡る[16]. 水で膨潤した SDS 及 びプロパノールの擬二分子膜は油中でラメラ構造 を形成し，膜に垂直な方向への散乱に膜厚のスケ 一ルで単純な拡散では説明出来ない余㮃運動項が 見られ，膜厚の摇らぎと解釈された[16]. この研 究の発展として, 我々は少量の油によって膨潤さ れたポリオキシエチレン系非イオン界面活性剤の 擬二分子膜の水中での運動を，膨潤度を変えなが ら測定した。膜厚を無視した一枚膜の曲げ摇らぎ モデル[17]によって NSE から得られた中間相関関 数を解析した結果，膜厚のスケールにおける余剒 運動項が Fig. 1 のように観測された。縦軸は中間 相関関数の緩和曲線から得られる緩和係数 動量遷移 $q$ の 3 乗で割った值, 横軸は $q$ である. 一枚膜の曲げ運動モデルは $\Gamma / q^{3}$ が $q$ に対して一定 值を示すのに対し，このデータは明らかなずれを 示す。このずれは，丁度 SANS データの極小が現 れる $q$ で極大となる。この結果は, 膜厚のスケー ルで曲げ運動では説明できない運動が表れること を示しており, 膜厚の摇らぎとして解釈できる.

Fig. 1 の $/ q^{3}$ のピーク高さは緩和時間に, ピークの 広がりは摇らぎの振幅に対応すると考えられる [10]. このような余唎運動項は散乱コントラスト によらずに見られること[11], 脂質二分子膜にも 現れること[18]が確認され，膜厚摇らぎは二分子 膜で一般的に見られる現象と考えられる.

次に，膨潤度を変えながら同様の測定を行った ところ， $\Gamma / q^{3}$ のピーク位置は膨潤度（膜厚）の増 加とともに低 $q$ 側へシフトし, 膜厚と NSE シグナ ルの相関関係がうまく説明できる．Fig. 2 には摇

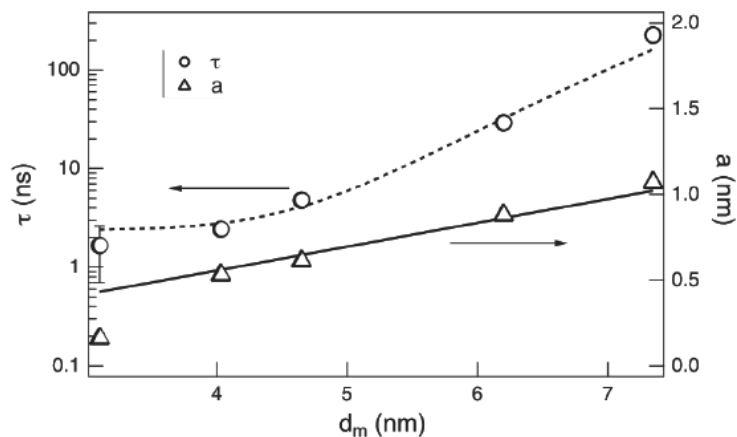

Fig. 2 Bilayer thickness $d_{\mathrm{m}}$ dependence of thickness fluctuation relaxation time $\tau$ and its amplitude $a$. Solid line shows the phenomenological relationship between the fluctuation amplitude and the bilayer thickness (see section 3 in the main text) and dashed line is the guide to the eyes.

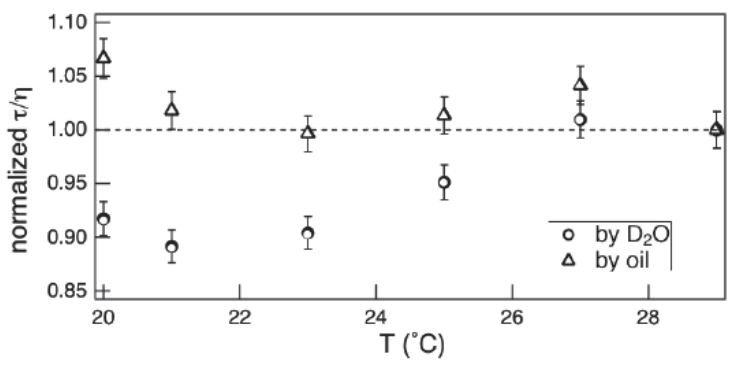

Fig. 3 Thickness fluctuation relaxation time, $\tau$, normalized to the solvent viscosity, $\eta$. The values are also normalized to the value at $T=29{ }^{\circ} \mathrm{C}$. The deviation is with in $5 \%$ when oil viscosity is used as $\eta$, while in $10 \%$ when water viscosity is used.

らぎの緩和時間 $\tau$ と摇らぎの振幅 $a$ を膜厚 $d_{\mathrm{m}}$ に対 してプロットした. ては厚みの増加とともに大きく なり, 無膨潤の二分子膜では数 ns の緩和時間だっ たものが厚みの増加とともに $100 \mathrm{~ns}$ のオーダー迄 上昇した。一方， $a$ は $d_{\mathrm{m}}$ に対してほぼ線形に増加 し，およそ膜厚の $10 \%$ 程度となった。厚み摇らぎ の振幅はコンピュータシミュレーションによる解 析結果と良く一致し，ここで観測された余剰運動 が膜厚の摇らぎであることが確認された[10].

一般に界面活性剂膜の運動は溶媒の粘性によっ て減衰する。例えば, 曲げ弾性運動の緩和時間は 溶媒粘度に逆比例する。そこで, 厚み摇らぎの緩 和時間と溶媒粘度の関係性を理解するために, 厚 夕摇らぎの温度依存性を調べた[11]. 温度下降に よる厚み摇らぎのパラメータはてを除いてほとん ど変化しない. Fig. 3 は温度 $29^{\circ} \mathrm{C}$ で規格化した, $\tau$

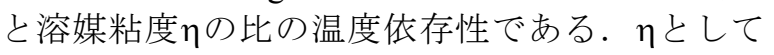
$\mathrm{D}_{2} \mathrm{O}$ の粘度を考慮した場合, 温度下降とともに $\tau / \eta$ は減少する。一方， 凤として膜内の油の粘度を考 慮した場合, $\tau / \eta$ は $5 \%$ 範囲内でほぼ一定となる。 すなわち，膜厚摇らぎの緩和時間の決定要因とし て膜外より膜内の溶媒粘度効果が重要であること, 従って，厚み摇らぎを特徵づける物理量は膜内の 相互作用や流体力学に依存する. 


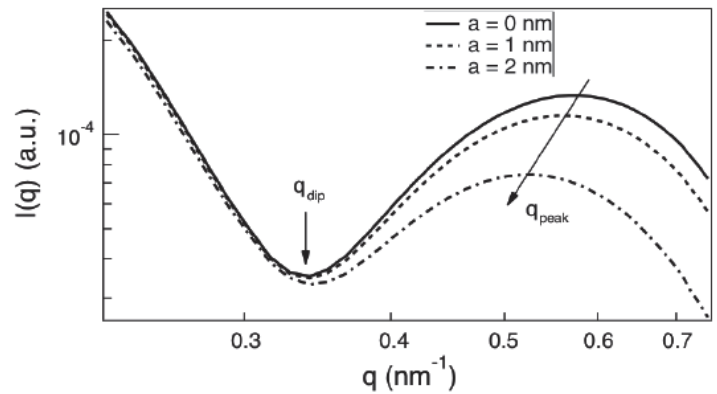

Fig. 4 Fluctuation amplitude, $a$, dependence of SANS profiles based on the computer model calculation. The dip position, $q_{\text {dip }}$, does not shift much with increasing $a$, while the peak position $q_{\text {peak }}$ shifts to lower $q$. Here the bilayer thickness, $d_{\mathrm{m}}$, is fixed at $10 \mathrm{~nm}$. The bilayer dimension and the wavelength of the fluctuation are assumed to be $500 \mathrm{~nm}$ and $5 \mathrm{~nm}$, respectively.

以上のように，NSE は界面活性剂膜の曲げ運動 のみならず，膜内の運動，ここでは厚み摇らぎ， について詳細に調べることが可能である.ただし， 現在のところ NSE データの解析は現象論的な取 り扱いにすぎない。本稿の後半では厚み摇らぎが 従う膜の変形自由エネルギーモデルの議論を紹介 するが，NSE データ解析と理論的な考察は今後の 研究を待たなければならない.

3. 膜厚摇らぎのコンピュータモデルによる解釈 一般的に形状因子の計算では，形状摇らぎを形 状多分散性として考慮し，動的な描像として解釈 されることは少ない.このため, 構造スケールの 分布は考慮されるが，運動との関連性については あまり検討されてこなかった。そこで，界面活性 剂膜の摇らぎを例にとり，形状因子に対する運動 の影響を簡単なコンピュータモデルを用いて検討 した。ここでは，膜が正弦波的な摇らぎを示す場 合の，いわゆる film contrastに対して見られる影 響を解析した。

まず正弦波の振幅 $a$ と波長入を一定にして膜厚 $d_{\mathrm{m}}$ だけを変化させた場合に計算される $I(q)$ の変化 を観測した． $d_{\mathrm{m}}$ を増大させると形状因子からくる 散乱の極大 $q_{\text {peak }}$ と極小 $q_{\text {dip }}$ の両方が低 $q$ 側へシフ 卜した。一方， $d_{\mathrm{m}}$ と入を一定にして $a$ だけを変化 させた場合，Fig. 4 に見られるように $a$ の増大に よって $q_{\text {peak }}$ は低 $q$ シフトするが, $q_{\text {dip }}$ はほとんど 変化しない.また, 入を変化させても $q_{\text {dip }}$ は変わら ない。これらの結果から膜厚の推定には $q_{\text {dip }}$ を使 用するのが有効であると言える。

二分子膜に平行な方向と $q$ ベクトルのなす角を $\theta$ とする. 特異的な配向の無いラメラ膜を考える と, $q$ ベクトルは全ての方向から均一にサンプリ ングされる。その場合, 平均の膜厚は $d_{\mathrm{m}}=2 \pi$ $\sin \theta_{\text {ave }} / q_{\text {dip }}$ と表される. $\theta_{\text {ave }}$ は $\theta$ の平均角度で約 32.7 度であると計算できる[13]. 過去の二分子膜の小 角散乱等の観測データを基に膜厚を解析したとこ ろ，この式が妥当である事がわかった[13].

次に, $\lambda$ が短い $\left(\lambda / d_{\mathrm{m}}<1\right)$ 場合の $a$ を $q_{\text {peak }}$ から 求める事を試みた。まず二分子膜が摇らぎのない
二枚の平行平面であるとした場合， $q_{\text {peak }}$ と $q_{\text {dip }}$ の 比が約 1.65 になる事が計算データから読み取れた. この值を基準に振幅の増減によるこの比の変化率 を観測したところ，以下の経験則が成り立つ.

$a \approx\left(\frac{1-0.61 \hat{q}}{15}\right)^{0.426} d_{m}$

ここで， $\hat{q}=q_{\text {peak }} / q_{\text {dip }}$ である. Fig. 2 の直線はこの 経験則による計算結果である。ここで紹介した SANS データから得られた $\hat{q}$ はおよそ 1.4 であつ た。ただし，膜厚 $d_{\mathrm{m}}=3.1 \mathrm{~nm}$ の二分子膜では，散 乱コントラストが十分でないために， $q_{\text {dip }}$ や $q_{\text {peak }}$ が計測不能で，ここでの理論的な枠組みから外れ る、そのため，このデータ点は除いた。眓から明 らかなように，この経験則は厚み摇らぎの振幅を 良く見積もっている.

このように SANS データは熱摇らぎの結果が構 造に与える影響を含んだ情報として処理すること が出来る。これらは一般に多分散性として処理さ れるが，多分散性の詳細な理解は系の運動状態を 理解する上での基本情報であり，散乱理論モデル やコンピュータによる計算と小角散乱及び NSE を組み合わせることにより，より深い系の理解が 可能であることを示す好例である。

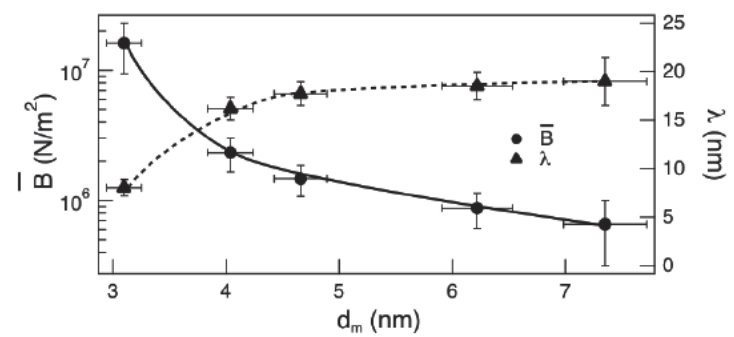

Fig. 5 Estimated values of thickness compressibility modulus $\bar{B}$ and the thickness fluctuation wavelength $\lambda$. The values for $d_{\mathrm{m}} \approx 3 \mathrm{~nm}$ is to the pure bilayer and the others for the oil swollen bilayers. Lines are the guides to the eyes.

\section{4. 厚み摇らぎと変形自由エネルギー}

脂質二重膜にタンパク質を埋め込む問題はその 生物物理化学的観点から広く研究されている。

1986 年に Huang が示した変形自由エネルギーは スメクティック A 液晶の弾性エネルギーモデルを 脂質膜の弾性モデルに拡張し，タンパク質の挿入 による膜の変形を記述する[4]. 単位膜面積当りの 自由エネルギー $f_{\mathrm{def}}$ は

$f_{d e f}=\bar{B} \frac{u^{2}}{h}+\frac{\kappa}{2}\left(\frac{\partial^{2} u}{\partial x^{2}}+\frac{\partial^{2} u}{\partial y^{2}}\right)^{2}+\gamma\left[\left(\frac{\partial u}{\partial x}\right)^{2}+\left(\frac{\partial u}{\partial y}\right)^{2}\right]$

で表される。第一項は膜の圧縮拡張に伴う変形を 表し $\bar{B}$ は膜の圧縮弾性率である。第二項は膜内部 広がり（splay）によるエネルギー損失を表す. splay 弾性率と曲げ弾性率の関係から係数にんが現れる。 第三項は界面エネルギー変化に対応し表面張力 $\gamma$ を係数とする. 膜の変形は $u$ で表され, $h$ は膜厚 の $1 / 2$ である.この変形自由エネルギーに基づき, 厚み摇らぎの振幅が膜の弾性定数を用いて表され 
る[4]. 我々の実験結果から得られた厚み摇らぎの 振幅をこのモデルと比較することにより，膜の圧 縮弾性率 $\bar{B}$ を決定した[15]. Fig. 5 は得られた $\bar{B}$ の 厚み依存性を示している。ここで，火はNSE 実験 から，hはSANS 実験から求められており， $\gamma$ は文 献值を用いた[19]. 無膨潤の二重膜では $\bar{B}=(1.6 \pm$ $0.7) \times 10^{7} \mathrm{~N} / \mathrm{m}^{2}$ が得られ，文献值 $3 \times 10^{6} \mathrm{~N} / \mathrm{m}^{2}$ [20] と比較可能である. 一方, 膨潤膜では膜の圧縮弾 性率が厚みに依存して小さくなることがわかる。

このように，厚み摇らぎを詳細に調べることによ り膜の圧縮弾性率を求めることが出来る.

一方，厚み摇らぎに伴う変形は膜面内では変形 中心から等方的に伝播するため, (2)式をシリンダ 一座標系に変換し，変形 $u$ を書き直す. Movileanu ら[7]のように自由エネルギーを書き下せば，変形 自由エネルギーの解析的な表式が得られる[15]. 面内の変形サイズが厚み摇らぎの波長に対応する と仮定すると, 変形自由エネルギーを最小化する 厚み摇らぎの波長が計算できる[15]. 得られた摇 らぎの波長入はFig. 5 に示したように, 二重膜では $10 \mathrm{~nm}$ 程度, 膨潤膜では $20 \mathrm{~nm}$ 程度となり, 無膨 潤の二重膜と膨潤膜とでは厚み摇らぎの波長に違 いが表れる。より圧縮されやすい膨潤膜は，溶媒 が膜内に侵入することにより摇らぎの波長を大き くしていると考えられる.エネルギーの表式(2)に 立ち返れば，圧縮されやすい膜は圧縮拡張項が小 さくなり splay 変形項が主要因となる.すなわち, splay 変形は波長の小さな厚み摇らぎを制限する 一方，圧縮拡張項は大きな波長を制限する。その バランスが入の決定要因である[15]. さらに，膜の 圧縮弾性率が油の混入によって変化したように, 膜への物質の混入は膜の弾性的な性質を変化させ, 摇らぎの性質に影響を及ぼす。このことは，例え ば細胞膜中のタンパク質の効果を理解する上で重 要であると考えられる。また油による膨潤膜の場 合には，2 節で紹介したように膜内の流体力学も 大切であり, この点も考慮して今後の理論的枠組 みを構築する必要がある。

5.おわりに

本稿では，界面活性剂膜の厚み摇らぎを SANS 及びNSEにより観測した結果を基に，コンピュー タモデルによる解析や理論モデルとの整合性を調 ベた結果を紹介した。界面活性剂分子の協同運動 が膜の弾性的性質と密接に関連することを改めて 理解するとともに，局所的な協同運動の観測が運 動の振幅や波長あるいは弾性定数等，より多くの 情報を提供可能であることを示した．本稿では割 愛したが，脂質二重膜の場合の厚み摇らぎの緩和 時間は $100 \mathrm{~ns}$ のオーダーであることが観測され [18], より高分解能な測定が不可欠となっている. ナノ秒付近で見られる平衡運動は, より長時間で 発達する動的な現象との関連も考えられ，興味深 い研究対象である. 本稿が今後の研究発展のアイ ディアに結びっくこととなれば幸いである.
謝辞

コンピュータシミュレーションは S. Chawang 氏と，小角散乱のモデル計算はV. Lee 氏と，自由 エネルギー計算は R. Ashkar 氏との共同研究であ る. P. Butler 氏の実験や議論への協力，瀬戸秀紀 氏の助言や激励, さらに，M. Watson 氏及び R. Bradbury 氏との有益な議論に感謝申し上げる。

参考文献

[1] W. Helfrich, Z. Naturforsch C28, 693 (1973).

[2] T. Takeda et al., J. Phys. Chem. Sol. 60, 1375 (1999).

[3] O. Holderer et al., Soft Matter 9, 2308 (2013).

[4] H.W. Huang, Biophys. J. 50, 1061 (1986).

[5] P. Helfrich and E. Jakobsson, Biophys. J. 57, 1075 (1990).

[6] C. Nielsen et al., Biophys. J. 74, 1966 (1998).

[7] L. Movileanu et al., Bull. Math. Biology 68, 1231 (2006).

[8] R. Phillips et al., Nature 459, 379 (2009).

[9] M. Nagao, Phys. Rev. E 80, 031606 (2009).

[10] M. Nagao et al., Soft Matter 7, 6598 (2011).

[11] M. Nagao, J. Chem. Phys. 135, 074704 (2011).

[12] E. Lindahl and O. Edholm, Biophys. J. 79, 426 (2000).

[13] V. Lee and T. Hawa, J. Chem. Phys. 139, 124905 (2013).

[14] V. Lee and T. Hawa, submitted.

[15] M. Nagao and R. Ashkar, in preparation.

[16] B. Farago et al., Physica B 213\&214, 712

(1995).; B. Farago, Physica B 226, 51 (1996).

[17] A.G. Zilman and R. Granek, Phys. Rev. Lett. 77, 4788 (1996).

[18] A.C. Woodka et al. Phys. Rev. Lett. 109, 058102 (2012).

[19] S.B. Hladky and D.W. Gruen, Biophys. J. 38, 251 (1982).

[20] P. Oswald and M. Allain, J. Physique 46, 831 (1985). 